\title{
Materials Research Priorities
}

\section{R. Chidambaram}

The following article is a speech by $R$. Chidambaram, principal scientific advisor to the government of India, delivered at the inaugural session of the 13th Annual General Meeting of the Materials Research Society-India (MRS-I) at Hyderabad on February 7, 2002. Slight modifications and an update were provided by the author. This article is reprinted with permission from the MRS-I Newsletter, Volume B 02, Number 2, April 2002.

Prof. C.N.R. Rao, Founder President of MRS-I—and, may I say, father figure to the Society, who has retained his tremendous enthusiasm for research as we saw just now-Prof. Chakravorty, Dr. Raghavan, Dr. Dipankar Banerjee, Prof. Subramanyam, distinguished materials scientists who have come for this meeting and friends: I thought that, in the brief time that has been given to me, I shall say a few things about what I consider as materials research priorities for India. Dr. Banerjee-not Dipankar, but our own brilliant Srikumar-and myself are now editing a book on materials research. It has gotten a little delayed because the receipt of a couple of articles got delayed. If you look at the subjects which have been covered, it is fascinating to see the excellent quality of the work that is going on in India in a variety of fields. We are looking both at the current scenario and the future projections. One thing is clear. More attention is needed to get technology pay-offs for India from the efforts that we are putting in.

Now, one can divide the materials research work into areas, though, of course, the boundaries are not sharp between basic research and applied research. For basic research, you need advanced facilities, you need advanced analytical equipment for materials characterization. Unless you have well-characterized samples, all data and results that you get become practically useless. This happened, for example, in the early days of high- $\mathrm{T}_{\mathrm{c}}$ superconductors. Basic research is important; it is a cultural necessity. Any civilized country must provide an opportunity for its highest intellects to work on problems of their choice. Applied research is also necessary to catalyze indigenous technology growth. Research instrumentation has to be developed and there is weakness here. Of course, there are exceptions. A great deal of instrumentation has been developed in the Department of Atomic Energy and some other laboratories and institutions. You heard just now how Prof. C.N.R. Rao's group built the 15-tesla magnet for his magnetoresistance studies. But our instrumentation efforts are inadequate.

Frontier areas of basic research are often decided by the technology imperatives of developed countries. They have already reached a high level of technology development. They want to carry out research to reach even higher technology levels. Of course, we must be in these areas, pursuing them as basic research and also as an investment for future-or, if possible, even current-technology development. At the same time, we should look also at the problems which are of immediate relevance for our own country.

Let me come now to the Synchrotron Radiation Sources [SRSs] which we are building for the first time in India at the Center for Advanced Technology [CAT], Indore. Building an SRS is like building a nuclear reactor. It requires not one technology, but a variety of scientific and engineering disciplines. For building a reactor, you need reactor physics, water chemistry, reactor engineering, control instrumentation, and a range of other engineering disciplines. In a similar way, for building an electron accelerator, an electron storage ring, it requires knowledge of high vacuum, RF systems, high voltage, beam dynamics, and other disciplines. The first electron storage ring, INDUS-I [located at CAT, Indore], which gives vacuum ultraviolet and soft $\mathrm{x}$-ray radiation, is already functioning; and INDUS-2 [to be located at CAT, Indore], which is a $2.5-\mathrm{GeV}$ ring with insertion

Material Matters is a forum for expressing personal points of view on issues of interest to the materials community. devices and will give hard $\mathrm{x}$-ray radiation, will be completed next year. INDUS2 will have provisions for a couple of dozen beamlines. Ten of the beamline instruments are being built by the units of the Department of Atomic Energy [seven by the Bhabha Atomic Research Center, Mumbai; two by CAT itself; and one by the Saha Institute of Nuclear Physics, Kolkata] and a couple by IUC-DAEF [Inter-University Center for DAE facilities]. But not enough people are coming forward from the university system to build beamline instruments, though there are excellent scientists in the country who would want to do basic research with the instruments once they have been built. We should examine what difficulties are holding them back from participating in instrumentation development and remove those impediments. Of course, it is time-consuming to build beamline equipment or any other advanced experimental equipment. But unless we do that in a big way, we will not be able to catch up, as Prof. C.N.R. Rao said, with the countries abroad.

If I come to applied research, a very successful example is the nuclear materials development program. Dr. Ganguly is here, one of the few persons who has worked with all kinds of nuclear fuelplutonium, uranium-233, natural uranium, enriched uranium. In applied materials research, also, you need advanced facilities, advanced analytical equipment. In addition, you must also have production facilities, and all this leads to indigenous technology development. The nuclear materials development program is not an isolated piece of development. You have to develop fuel, you have to develop cladding material, you have to develop fuel assemblies and test them for quality. You have to make the whole program consistent with the reactor's objectives. Dr. Rodrigues is here, who did a great deal for the development of [the] fast breeder reactor at Kalpakkam, which is the second stage of our nuclear power program. Here we need mixed plutonium-uranium fuels [and] thorium-based fuels; breeding ratios have to be estimated. In applied materials research, we have been successful in specific advanced mission-oriented areas.

There has been some debate in recent literature between conventional science vs. strategic science. Personally, I do not see a sharp border between the two. Take my own area of high-pressure physics. High pressure as a parameter is fascinating. If you heat a material, by the time it expands by $10 \%$, it has melted. But you can squeeze a material to half its volume and more, and still do experiments at room temperature 
or at other temperatures. You can do [this] under isothermal conditions or you can send shock waves inside. Shock waves inevitably heat the material, along with compressing it. We started working on transition metals because Mr. C.V. Sundaram brought a paper from Cambridge by Pettifor, who said that here the phase stability is decided by $d$-band occupancy. As you know, if you squeeze a material, the bands expand and there could be an $s-d$ electron transfer and a phase transition can take place. We have played around with phase-transition pressures; you can add vanadium to titanium, for instance, and bring down the transition pressure. Now, one could call this phasetransition study as conventional science.

We have worked on rare earths and on actinides. Thorium is a $5 f$ metal, and if you want to get a good equation of state (EOS) for thorium and the right pressure for its transition, you must study the broadening of the $5 f$ band. This can be very exact, using the density functional method and a powerful computational resource. My colleagues have published papers on this in Physical Review. You could call this conventional science. But when we work on plutonium, which is a few atomic numbers up the periodic table, and do the same thing, you could call it strategic science. If you want to predict exactly the yield of a fission weapon, you must know exactly the EOS of plutonium and uranium. So, where does conventional science end and strategic science begin? So, my feeling is that when we are doing materials research-or for that matter, any kind of research-we should not get too worked up about such semantic boundaries between basic research vs. applied research, small science vs. big science, etc.

We should also forget about what the institutional attachment of a scientist is and concern ourselves only about the quality of his research. I remember the days many years back when I and Milan Sanyal were trying to get our group into the collaborative access team for building a beamline instrument for the Advanced Light Source at Argonne [National Laboratory, USA]. The potential members of the team were the Brookhaven National Lab [USA], Argonne National Lab, a U.S. university, and BARC. While the design discussions were going on, institutional affiliation did not concern anybody. We were willing to build a part of the instrument at our cost. Incidentally, the reason we got out of the project was that the question of paying for the maintenance of the beamline came up. Imagine having to continuously pay a fraction of the salaries of two American technicians for maintaining the beamline!

Why do we do materials research? If someone tries to understand and find out the behavior of materials just from the point of view of acquiring knowledge, we don't have to ask why the study is being done-only about the quality of the work. But if the work is articulated as being related to technology development, the linkage to Indian industry has to be established early. What is the purpose of technology development in general? Creating national wealth; improving quality of life, particularly in rural areas; and enhancing national security! And here comes the question of technology foresight. This is different from technology forecasting. If you ask if human cloning will work or will DNA computing become practical and look at it purely from a scientific and technological angle, that is forecasting. But add to it assessment from an economic, social, environmental, and (in the case of human cloning) ethical point of view, it becomes technology foresight. Technologyforesight analysis helps to decide what are the critical technologies for a country at any point of time. You would get different answers, depending on whether you are from [the] USA or from India. We can do this for all materials-related technologies. So when you talk of technology, you have to consider how it feeds into the Indian system. Are there Indian industries which are ready to take over the development of these technologies, or how [should they] be helped to do so? This was what was done for the nuclear materials-related technologies.

Let me close with one last thought. In my new assignment as principal scientific advisor to the government of India, it has become very clear to me that ruraldevelopment-related technologies must be given the highest priority. Two-thirds of Indians live in villages. Increase in agricultural productivity through use of known science and technology in the poorest rural parts of the country can take the people living there above the poverty line. Beyond that, agriculture productivity can have limits, unless simultaneously we can create jobs outside the primary farm and related sectors. And this is being done in the Tenth Plan [successive fiveyear plans of the Government of India; the present Tenth Plan started in April 2002]. Value-addition by food processing [fruit products, potato chips, fish papad], for instance! The other kind of technologies which can be developed with rural areas in mind can also become important, for adding value and for creating new job opportunities. In fact, sometime I am going to suggest to Prof. Subramanyam and Prof.
Chakravorty that MRS-I should have a new subject group on rural-developmentrelated materials. I feel many of us can improve the materials which rural artisans and agriculturists use. TIFAC [the Technology Information, Forecasting, and Assessment Council], which is a part of the Department of Science and Technology, has done some interesting work on use of coir, bamboo, etc. and Prof. Ramachandra Rao showed me recently in NML [National Metallurgical Laboratory, a laboratory of the Council of Scientific and Industrial Research at Jamshedpur] a simple device to remove drudgery from the work of a blacksmith. So, we can contribute to materials and materials processing technologies related to rural development. MRS-I over the years has grown from strength to strength in a way even I did not expect when Prof. C.N.R. Rao started it, and we should also now see how much we can contribute to rural development.

[Update: A Subject Group on "Materials for Rural Development" is being formed in the MRS-I. Another interesting development is the Workshop on "Rural Pottery" held jointly by TIFAC and the Akhil Bharatiya Gramodyog Mahasangh (All India Rural Industries Federation) on June 19, 2002, at Jaipur, where we brought together rural potters and the ceramics specialist Mr. Swapan Guha of the Jaipur Ceramics (Private) Limited, who make world-class bone-chinaware. Mr. Guha demonstrated how the rural potters could, with minor changes in their equipment and processing techniques, go from traditional terracotta to much higher-valued glazed terracotta and stoneware.]

R. Chidambaram is the principal scientific advisor to the government of India and is past president of the Materials Research Society-India. He joined the Bhabha Atomic Research Center (BARC) in 1962, became its director in 1990, and is currently the Department of Atomic Energy Homi Bhabha Chair Professor. He served as chair of the Atomic Energy Commission and secretary to the government of India in the Department of Atomic Energy from February 1993 to November 2000. Chidambaram is a fellow of all of the major science academies in India and also of the Third World Academy of Sciences in Trieste, Italy. He chaired the Board of Governors of the International Atomic Energy Agency (IAEA) during 1994-1995. Until recently, he was vice president of the International Union of Crystallography. Chidambaram is currently chair of the council and the governing body of the Technology Information, Forecasting, and Assessment Council (TIFAC). He received his $P h D$ and DSc degrees from the Indian Institute of Science, Bangalore, and holds honorary DSc degrees from several Indian universities. 